Document downloaded from:

http://hdl.handle.net/10251/102296

This paper must be cited as:

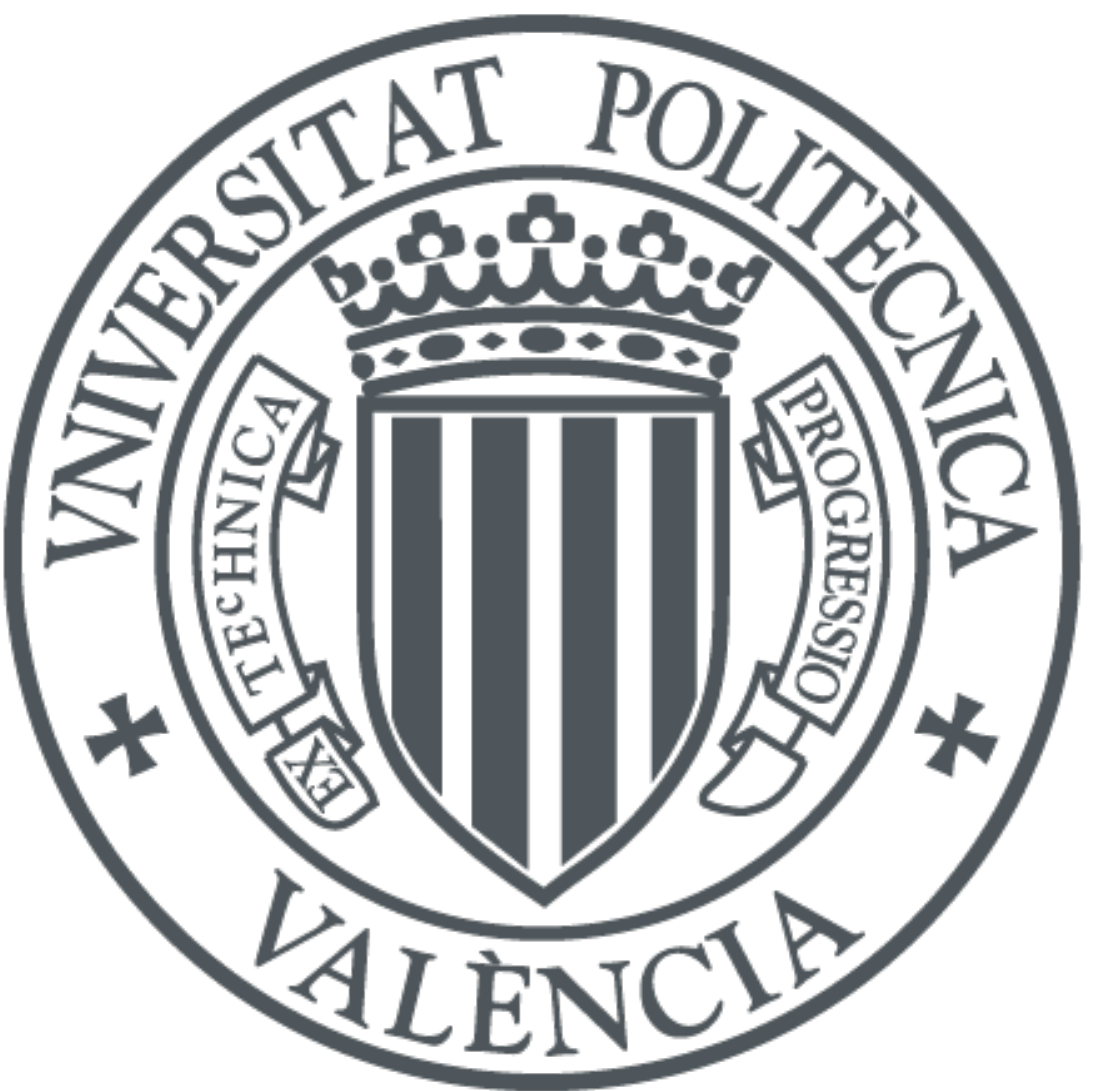

The final publication is available at

https://doi.org/10.1016/j.compedu.2008.09.015

Copyright Elsevier

Additional Information 


\title{
Learning the Attachment Theory with the CM-ED Concept Map Editor
}

\author{
U. Rueda ${ }^{1}$, A. Arruarte ${ }^{1}$, J. A. Elorriaga ${ }^{1}$, E. Herrán ${ }^{2}$ \\ ${ }^{1}$ Computer Languages and Systems Department \\ ${ }^{2}$ Developmental and Educational Psychology \\ University of the Basque Country (UPV/EHU), 649 P.K., E-20080 Donostia \\ \{urko.rueda, a.arruarte, jon.elorriaga, elena.herran\}@ehu.es \\ Fax: +34943015590 \\ Tel: +34943015065
}

\begin{abstract}
This paper presents a study carried out at the University of the Basque Country UPV/EHU with the aim of evaluating the CM-ED Concept Map EDitor with Social Education students. Concept mapping is a widely-accepted technique that promotes meaningful learning. Graphically representing concepts of the learning domain and relationships between them helps students integrate new knowledge into their current cognitive structure. Due to the flexibility of computer-aided drawing graphs, several concept mapping tools have been developed and their use has been studied over the last few years. CM-ED is a multilingual and multimedia software program designed for drawing concept maps. Until recently, CM-ED had been mainly used and evaluated in Computer Science university degree. This paper represents a qualitative step in the evaluation of CM-ED: from technical students to students of more theoretical fields. The main characteristics of the $C M-E D$ editor and the carried out study are presented in this paper.
\end{abstract}

Keywords: Concept maps, Concept Map Editor, Evaluation of CAL systems, Improving classroom teaching, Postsecondary education

\section{Introduction}

Ever since Novak [1] placed concept mapping on the educational agenda as a method to graphically represent knowledge, it has become an increasingly popular advanced teaching and learning tool. Many studies have shown that learners benefit from the use of concept mapping as both a method and as a teaching aid (Moen, 1997). The fundamentals of concept mapping are laid out in Ausubel's learning theory, which is based on the assumption that meaningful learning occurs when new concepts are linked to familiar concepts existing in the learner's cognitive structure (Ausubel, 1968). Ausubel's theory concludes that the learning of new knowledge depends on what is already known. A concept map is a graphical way of representing and organizing knowledge (Figure 1). It is comprised of nodes and links, arranged in some order to reflect the information of the domain being represented. Nodes symbolize concepts and links represent the relationship between concepts. Both concepts and links are labeled and may be categorized.

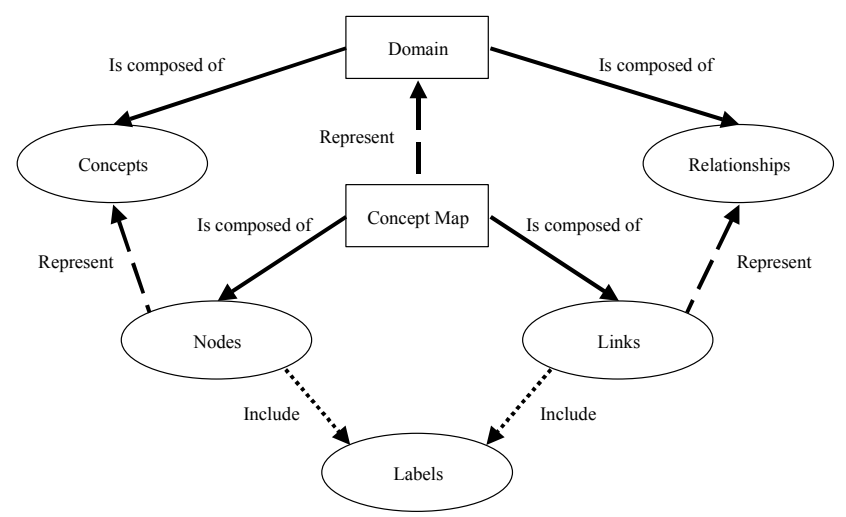

Figure 1. Example of a concept map

Although concept maps have been demonstrated to be a powerful instructional tool in different educational areas, most studies carried out with concept map software have been focused on scientific and technical areas such as physics [2], chemistry [3], math [4], therapeutic education [5], pharmacology [6], nursing education [7] or in secondlanguage acquisition [8] [9]. Less attention has been given to theoretical areas such as literature [10] or social science [11]. This tendency was also reflected in the proceedings of the first and second edition of the International Conference on Concept Mapping, held in Pamplona in 2004 [12] and San José in 2006 [13]. Concept maps have been identified as an important tool for support learning on a variety of levels, spanning kindergarten [14] to university [15] and 
even to distance education [16] [17] and web-based education [18].

A study conducted with the aim of evaluating the CMED Concept Map EDitor with Social Education students is presented in this paper. Until recently, CM-ED had been mainly used and evaluated by Computer Science students or by people in charge of applying Technology Enhanced Learning in primary and secondary schools. This work represents a qualitative step in the evaluation of CM-ED: from technical users to liberal arts students.

The paper is structured as follows: First, the main characteristics of CM-ED are reviewed, followed by the design issues and procedure of the study carried out. Next, the results of the study are analyzed and discussed. Finally, conclusions and future research are presented.

\section{CM-ED Concept Map EDitor}

CM-ED (Concept Map EDitor) is a software program for concept maps (http://galan.ehu.es/Galan). A concept map is a visual way of representing knowledge in which concepts, relationships (between concepts) and propositions (formed by the union of concepts through relationships) exist. The visual representation of a concept map takes the form of a graph. In graphs, concepts are visually represented through nodes and relationships through links. While nodes are closed geometric shapes (e.g. rectangles), lines are links that connect at least two nodes. Nodes and links can contain a label. A label is text that brings meaning to concepts and relationships.

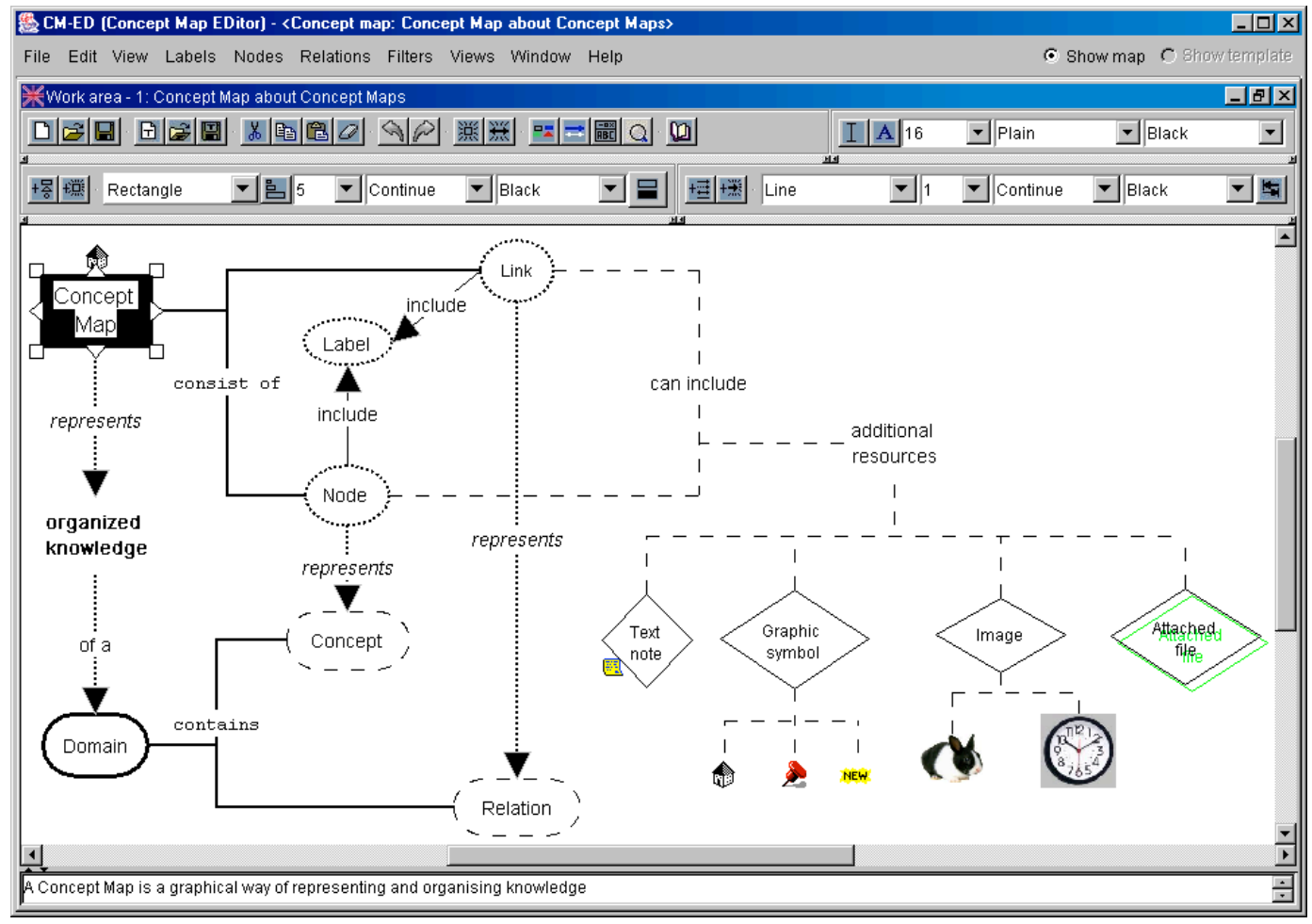

Figure 2. Interface of CM-ED

CM-ED takes advantage of Information and Communication Technologies (ICT) and allows the interconnection of multimedia resources and concept maps. A graphic resource is a visual property which, when applied to nodes, links and labels, changes their visual aspect (e.g. forms, colors, lines thickness, etc.) can represent information of the domain in the nodes and links. A multimedia resource is an electronic file attached to a node or link (e.g. text documents, images, audio, video, etc.). In addition, ICT enables the use of templates. A template specifies semantic information to nodes and links depending on their visual aspect; types of nodes and types of links.

CM-ED includes the following mechanisms for editing/visualizing concept maps:
- Flags and icons: the tool allows users to flag nodes and links and also to use icons and resizable images as nodes.

- Filters and views: filters are defined as types of nodes/links of a template which reduce the information displayed (hiding certain nodes/links). On the other hand, views allow for the definition of different organizations of the same concept map.

- Hiding: parts of the concept map can be hidden to reduce the cognitive load.

- Grouping: details of the concept map can be abstracted by grouping sets of nodes.

- Exploration: zoom function for displaying concept maps at greater or lesser detail. 
- Multilayered concept maps: enable the navigation of concept maps connected with hyperlinks.

- Multilingual concept maps: represent the same concept map in several languages.

The interface of the tool (see Figure 2) is composed of three areas. The main area, the central part of the figure, corresponds to the part of the screen in which the concept map is shown and modified. The operations are included in the menu bar (upper part of Figure 2), in tool bars and also in contextual menus. Moreover, some frequently used operations (e.g. node resizing, node linkage, etc.) can be performed directly in the central part of the screen. Thus, the user can choose her/his preferred way of working. On the notepad, located at the bottom of the window, the user writes her/his comments related to a node or relationship.

\section{Study}

In this section, the conducted study or experience is presented. The design issues, participants, instructors, instructional material, learning resources and procedure are described.

\subsection{Design}

This study took place during the first term (2007/2008) in the compulsory Developmental Psychology course of the Social Education program at the University of the Basque Country. As this first course subject is offered in both Basque and Spanish, students can choose the language in which they will take the class.

The aim of the study was to evaluate the possibilities that CM-ED offers for learning non-technical material and for students that were mostly unfamiliar with computers. Within the course, the Attachment Theory [19] was the topic chosen for working with CM-ED.

\subsection{Participants}

A group of 163 students (102 and 61 students enrolled in Basque and Spanish, respectively) was invited to participate in the study. However, due to several reasons, different numbers of students participated in each phase. This was principally due to the fact that the study lasted four months and the level of student dedication and initiative, which was higher at the beginning and at the end of the study, varied during this time. In addition, as some of the learning activities were planned to be carried out during regular class time, not all the enrolled students in the subject were expected to participate in every phase. In subsection 3.5 , the number of participants of the main phases is detailed and the final results take these circumstances into account.

\subsection{Instructors}

Three teachers and a PhD student participated in the study. One teacher was in charge of teaching the subject. She had been teaching this course for 11 years and was well trained in creating and assessing concept maps created with paper and pencil (P\&P). The other two teachers and the PhD student, developers of CM-ED, were members of the GaLan research group of the Computer Languages and Systems department at the same university.

\subsection{Instructional materials}

A number of bibliographical references [20] [21] and a nine-page summary written both in Basque and Spanish constituted the instructional materials for the attachment theory. The attachment theory is a psychological, evolutionary and ethological theory that provides a descriptive and explanatory framework for the discussion of interpersonal relationships between human beings. Four main parts of the theory were analyzed: introductory aspects of the attachment theory and attachment behavior in infants, adolescents and adults.

Students were also provided with handouts that included an introduction to concept mapping and examples of wellconstructed concept maps. The teacher of the subject introduced some aspects of the attachment theory using this method.

In terms of CM-ED, computer instructors provided students with instructions for downloading and installing the software and an online user guide.

\subsection{Procedure}

The study consisted of eight phases: (1) content teaching sessions (2) CM-ED presentation and pre-testing, (3) student team formation, (4) CM-ED installation, (5) concept map development, (6) post-testing, (7) final concept map collection, evaluation and discussion, and finally, (8) an exam.

- Content teaching sessions. Students received nine introductory sessions on the subject of attachment theory and a one-session theoretical introduction to the concept mapping strategy. Each session took 60 minutes. The subject teacher oversaw this activity.

- CM-ED presentation and pre-testing. In one laboratory session (students were separated into four groups), students were briefly presented with the main characteristics of CM-ED and given time to practice with it. After that, 116 participants completed an anonymous pre-test during the same session. The test allowed participants to give both their first impressions of CM-ED and to evaluate their experience using concept maps and related software programs. The questionnaire included questions about the following issues: ease of use, CM-ED vs. P\&P, the utility of CM$\mathrm{ED}$, opinion about the features of CM-ED and open questions asking for general feedback. 


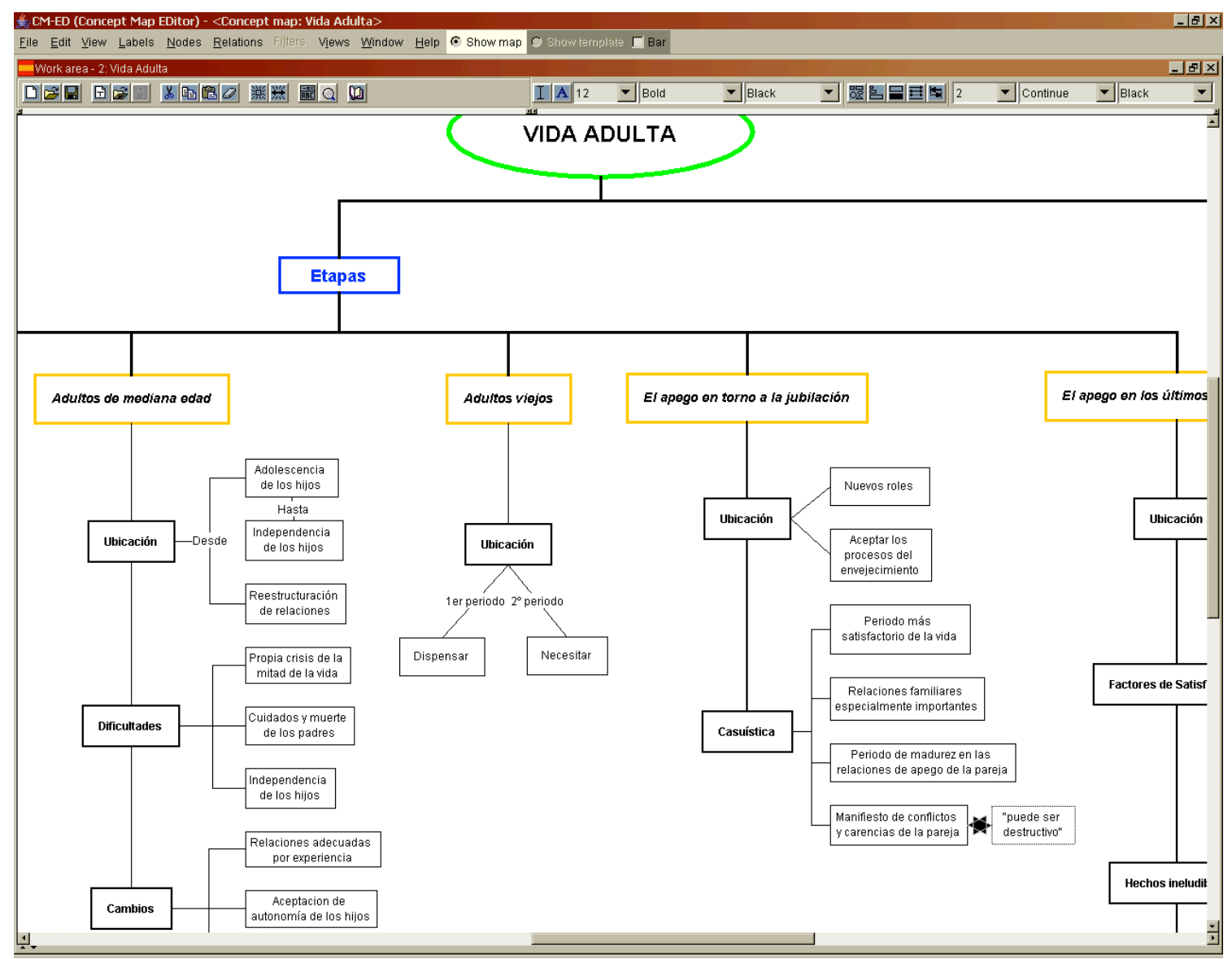

Figure 3. Example of concept map drawn using CM-ED

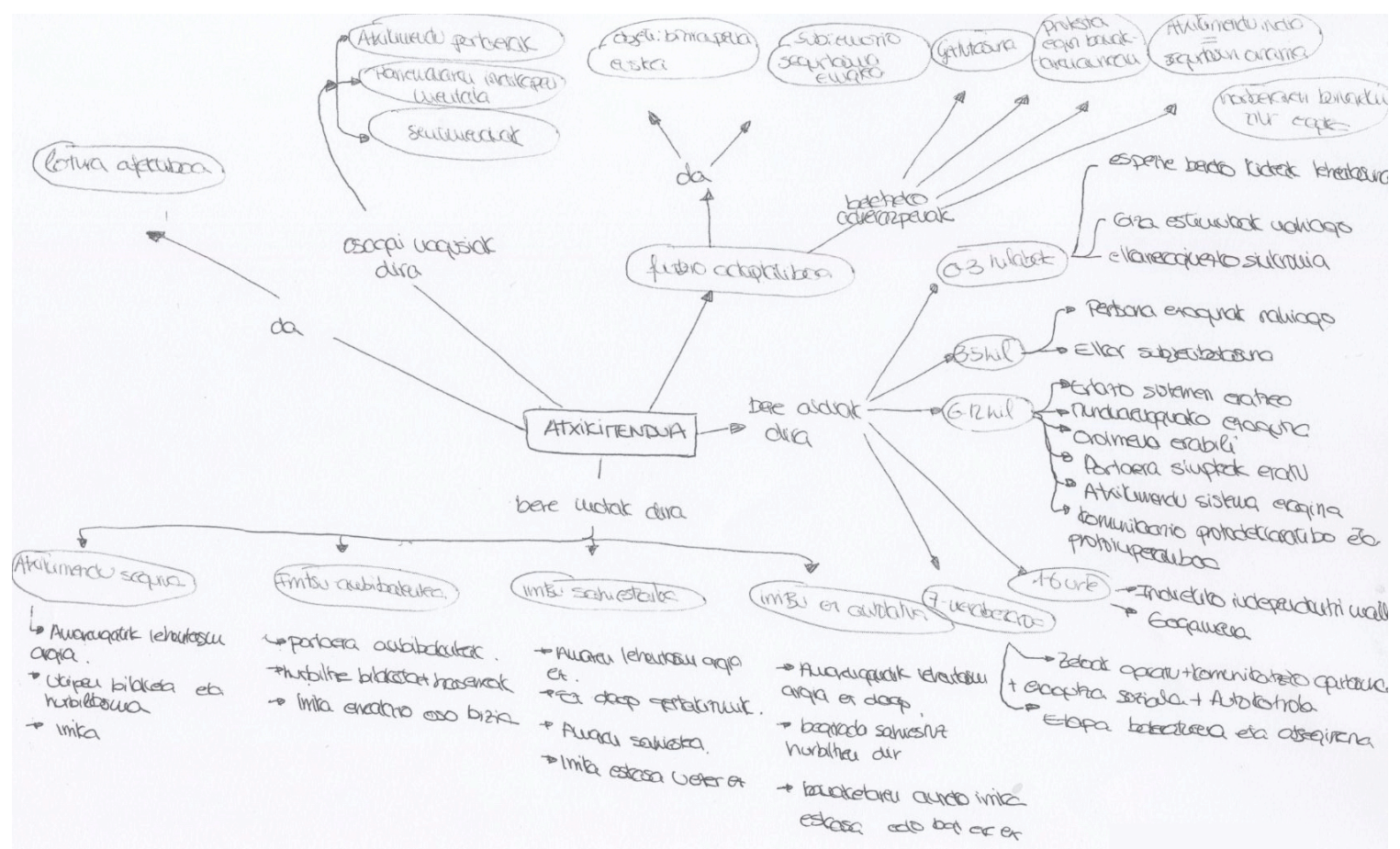

Figure 4. Example of a concept map drawn using P\&P 
- Student team formation. Before work on the concept map commenced, the students divided themselves into teams of three and decided if they were going to create the concept map using P\&P or CM-ED. No restrictions were established regarding how teams would work together. Only the final results, not the collaborative knowledge construction process, were to be evaluated in this study. Students who weren't able to attend the lectures were allowed to complete the work individually.

- CM-ED installation. The students were asked to download the editor from the web and install it on their own computers.

- Concept map development. Students had nine weeks to work on the generated map before turning it in. During this period of time students worked autonomously but had access to both the course instructor and the computer instructors in case they needed assistance. The fact that the concept map could be drawn first with $\mathrm{P} \& \mathrm{P}$ before creating it in CM-ED was of considerable interest to the authors. Therefore, a rough draft of the concept map was collected during this phase, nearly three weeks before the final map was to be turned in. Figure 3 and 4 show two examples of concept maps of the studied subject (Appendix A contains the English translation of both concept maps using CM-ED). Originally, the first one was generated using CM-ED; the second one using $\mathrm{P} \& \mathrm{P}$

- Post-testing. During a 20-minute session, 64 students completed a second, anonymous questionnaire. Questions dealt with the following: experience with concept maps and related software programs, concept maps and CM-ED learning, subject learning through concept maps, chosen working mode (P\&P, CM-ED, other software program) and preference of use, usefulness of multilingual and collaborative concept maps, usefulness of features included in CM-ED, concept maps and CM-ED usefulness for other subjects and purposes, general score of CM-ED and problems encountered throughout the study. Section 4 goes into those issues in greater depth.

- Final concept map collection, evaluation and discussion. The teacher collected the concept maps from 134 students, assessed them and selected five to discuss with students during one 60-minute course session.

- Final exam. Of the final exam's 30 questions, four were taken from the from the attachment theory topic.

\section{Results and discussion}

After a thorough analysis of the concept maps, questionnaires and final exam marks, the results yielded from the overall experience are separated into three main groups: results related to the learning of the subject domain, effects on the learning of the concept mapping learning strategy and the relevance of CM-ED on several levels.
Firstly, it should be mentioned that almost all the students, $82.2 \%$, took part in the study. However, they exhibited varying levels of commitment.

The fact that questionnaires were anonymous makes it impossible to establish a direct relationship between students' marks and their opinions about concept mapping strategy and CM-ED software. However, it was possible to study the relationship between concept map quality and the final exam mark.

On the one hand, the teacher was in charge of analyzing the generated concept maps and exams.

On the other hand, the responsibility of analyzing the questionnaires mainly fell on computer instructors. After a simple glance, instructors observed notable differences in the performance between the students depending on their knowledge and familiarity of ICT and concept mapping. No participant had had any experience whatsoever with concept mapping before this study. In terms of ICT use, only $35 \%$ were familiar with ICT.

In addition, many students encountered general technical problems not directly related to the study. For example, some students had problems downloading, installing, and executing CM-ED. Therefore, the first conclusion of this study is that these kinds of students need to have the software already installed and a more extensive training session. The authors tried to treat these situations separately when evaluating the results in order to focus on the effects of using concept maps and CM-ED on learning.

With those difficulties in mind, four student subgroups $\left(\mathrm{CM}_{\mathrm{x}}, \mathrm{CM}_{\sqrt{ }}, \mathrm{ICT}_{\mathrm{x}}\right.$, and ICT $\left.\sqrt{ }\right)$ were identified and the data of the questionnaires were treated separately in the analysis:

- $\mathbf{C M}_{\mathbf{x}}: 33$ students with problems using concept maps.

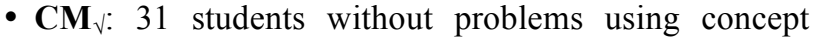
maps.

- ICT $: 42$ students with problems using ICT

- ICT $\sqrt{ }: 22$ students without problems using ICT

$\mathrm{CM}$ and ICT are not disjoint sets (the same students appear in both groups) while $\mathrm{CM}_{\mathrm{x}}$ and $\mathrm{CM}_{\sqrt{ }}$ are disjoints (a particular student belongs only to one of the sets). Similarly, $\mathrm{ICT}_{\mathrm{x}}$ and $\mathrm{ICT}_{\sqrt{ }}$ are also disjoint sets.

Despite having difficulties with or not being previously familiar with CM and ICT, $88 \%$ of participants affirm that they were able to learn the subject using concept maps. This is a really positive starting point.

\subsection{Concept Mapping Strategy}

The data analyzed in this section comes from the two questionnaires completed by the students. Students were asked whether or not they learned the concept mapping technique. $95 \%$ of the feedback was positive for the ICT $\sqrt{ }$ group, $52 \%$ for the $\mathrm{ICT}_{\mathrm{x}}$ group, $77 \%$ for the $\mathrm{CM}_{\sqrt{ }}$ group and $64 \%$ for the $\mathrm{CM}_{\mathrm{x}}$ group (see Table a). Overall, student groups provided a range of positive feedback, starting at $50 \%$ and peaking at $95 \%$. Therefore, students were convinced that software such as CM-ED helped them learn concept map strategy when unhindered by ICT issues. 
After the first session - CM-ED presentation and pretesting $-59 \%$ of the students claimed to be able to work with concept maps to some degree (note that in the pre-test, students were not yet grouped). However, this number reached $72 \%$ post-project. Though the use of CM-ED with respect to $\mathrm{P} \& \mathrm{P}$ is lower for the $\mathrm{ICT}_{\mathrm{x}}$ group (see Table c), students who didn't have problems using ICT learned the concept map technique with CM-ED.

\begin{tabular}{|c|l|l|l|l|}
\hline $\begin{array}{l}\text { Mastering the } \\
\text { concept mapping } \\
\text { technique }\end{array}$ & $\mathbf{C M}_{\sqrt{ }}$ & $\mathbf{C M}_{\mathbf{x}}$ & ICT $_{\sqrt{ }}$ & ICT $_{\mathbf{x}}$ \\
\hline Before the project & \multicolumn{4}{|c|}{$59 \%$} \\
\hline $\begin{array}{c}\text { After the } \\
\text { project }\end{array}$ & \multicolumn{3}{|c|}{$72 \%$ (whole group) } \\
\cline { 2 - 5 } & $77 \%$ & $64 \%$ & $95 \%$ & $52 \%$ \\
\hline
\end{tabular}

Table a). Mastering the concept mapping technique

When it came to the usefulness of concept maps, students had the following opinion: The majority of students $(69 \%)$ agreed that concept mapping is a useful learning strategy for a variety of subjects. Furthermore, $59 \%$ of the $\mathrm{CM}_{\sqrt{ }}$ group considered concept maps to be useful for other purposes (e.g. studying for an exam, organizational purposes).

\subsection{CM-ED.}

Like the previous section, the data analyzed in this section comes from the two questionnaires that the students filled out. Participants were generally positive when asked about whether or not they learned how to use CM-ED (see Table b). $86 \%$ of the ICT $\sqrt{ }$ group, $35 \%$ of the $\mathrm{ICT}_{\mathrm{x}}$ group, $72 \%$ of the $\mathrm{CM}_{\sqrt{ }}$ group and $41 \%$ of $\mathrm{CM}_{\mathrm{x}}$ group gave positive feedback in this regard. The authors conclude that the lack of previous knowledge of concept maps and difficulties when using ICT is significant in the learning of CM-ED. Obviously, the ability to learn CM-ED is much higher in the ICT $\sqrt{ }$ group.

\begin{tabular}{|c|c|c|c|c|c|}
\cline { 2 - 6 } \multicolumn{1}{c|}{} & $\mathbf{C M}_{\sqrt{ }}$ & $\mathbf{C M}_{\mathbf{x}}$ & $\mathbf{I C T}_{\sqrt{ }}$ & $\mathbf{I C T}_{\mathbf{x}}$ & $\begin{array}{c}\text { Whole } \\
\text { Group }\end{array}$ \\
\hline $\begin{array}{c}\text { Learning of CM- } \\
\text { ED }\end{array}$ & $72 \%$ & $41 \%$ & $86 \%$ & $35 \%$ & $58.5 \%$ \\
\hline $\begin{array}{c}\text { Positive opinion } \\
\text { of CM-ED }\end{array}$ & $69 \%$ & $25 \%$ & $82 \%$ & $23 \%$ & $49.75 \%$ \\
\hline $\begin{array}{c}\text { Difficulties with } \\
\text { CM-ED }\end{array}$ & $20 \%$ & $78 \%$ & $27 \%$ & $64 \%$ & $47.25 \%$ \\
\hline
\end{tabular}

Table b). Mastering CM-ED

When looking at the student groups as a whole, $50 \%$ had a positive opinion about CM-ED (Table b). Taking into account the problems with concept map strategy and with ICT, the result is satisfactory. More specifically, $82 \%$ of the $\mathrm{ICT}_{\sqrt{ }}$ group and $23 \%$ of the $\mathrm{ICT}_{\mathrm{x}}$ group viewed CM-ED in a positive light. In addition, the $\mathrm{CM}_{\sqrt{ }}$ group showed a positive rating of $69 \%$, while the $\mathrm{CM}_{\mathrm{x}}$ group showed one of $25 \%$. A strong correlation can be seen between the positive evaluation of CM-ED and the familiarity with concept map strategy and ICT.
As previously stated, the authors wanted to know whether or not the students had drawn the concept map with P\&P before doing it with CM-ED. In order to study this issue, the instructors collected a rough draft of the concept map. At that time, most of the students $(93 \%)$ carried out the exercise using CM-ED, $14 \%$ directly and $79 \%$ first drawing the concept map with $\mathrm{P} \& \mathrm{P}$ and later transferring it to CM-ED (Table c). Only 7\% of the students chose to use only P\&P. When considering this, along with the fact that $66 \%$ of participants had problems using ICT and, all of them were familiar with $\mathrm{P} \& \mathrm{P}$, the results are very positive. The following percentages chose CM-ED: $17 \%$ of the $\mathrm{CM}_{\sqrt{ }}$ group, $9 \%$ of the $\mathrm{CM}_{\mathrm{x}}$ group, $4 \%$ of the $\mathrm{ICT}_{\mathrm{x}}$ group and $27 \%$ of the ICT $\sqrt{ }$ group (14\% on average). Mixed usage of $\mathrm{P} \& \mathrm{P}$ and CM-ED was selected by $73 \%$ of the ICT $\sqrt{ }$ group, $78 \%$ of the $\mathrm{ICT}_{\mathrm{x}}$ group, $80 \%$ of the $\mathrm{CM}_{\mathrm{x}}$ group and $83 \%$ of the $\mathrm{CM}_{\downarrow}$ group (79\% on average). $11 \%$ of the $\mathrm{CM}_{\mathrm{x}}$ group and $18 \%$ of the $\mathrm{ICT}_{\mathrm{x}}$ group used $\mathrm{P} \& \mathrm{P}$, whereas nobody in the $\mathrm{CM}_{\sqrt{ }}$ and ICT $\sqrt{ }$ groups chose to do so. Again, there is a strong correlation between the selection of CM-ED and familiarization with ICT.

\begin{tabular}{|c|c|c|c|c|c|}
\cline { 2 - 6 } \multicolumn{1}{c|}{} & $\mathbf{C M}_{\sqrt{ }}$ & $\mathbf{C M}_{\mathbf{x}}$ & $\mathbf{I C T}_{\sqrt{ }}$ & $\mathbf{I C T}_{\mathbf{x}}$ & $\begin{array}{c}\text { Whole } \\
\text { Group }\end{array}$ \\
\hline $\begin{array}{c}\text { Directly with CM- } \\
\text { ED }\end{array}$ & $17 \%$ & $9 \%$ & $27 \%$ & $4 \%$ & $14 \%$ \\
\hline $\begin{array}{c}\text { First P\&P and later } \\
\text { CM-ED }\end{array}$ & $83 \%$ & $80 \%$ & $73 \%$ & $78 \%$ & $79 \%$ \\
\hline Only P\&P & $0 \%$ & $11 \%$ & $0 \%$ & $18 \%$ & $7 \%$ \\
\hline
\end{tabular}

Table c). Methods used to draw concept map

It is remarkable that those students who were most familiar with ICT had less difficulty with concept map strategy using CM-ED. One possible reason may be the use of CM-ED's error correction feature in the development of concept maps using CM-ED, as $\mathrm{P} \& \mathrm{P}$ requires much more effort when doing corrections. Surprisingly more difficulties arose in the $\mathrm{CM}_{\mathrm{x}}$ group, where $78 \%$ of students experienced problems using CM-ED. $64 \%$ of the $\mathrm{ICT}_{\mathrm{x}}$ group suffered similar difficulties. A plausible reason is that students from the $\mathrm{CM}_{\mathrm{x}}$ group were used to drawing concept maps with P\&P. The results of the more knowledgeable groups were as follows: only $20 \%$ of the $\mathrm{CM}_{\sqrt{ }}$ group and $27 \%$ of the ICT $\sqrt{ }$ group experienced problems. It should be noted that difficulties with concept map strategy and ICT are linked to the use of concept map software programs such as CM-ED.

Results related to the usefulness of CM-ED are as follows: $52 \%$ thought that CM-ED is useful for learning subjects while $35 \%$ believed it could be applied to other purposes.

$85 \%$ of students believed that multilingual concept maps were appropriate while $69 \%$ felt the same towards the collaborative construction of concept maps.

Most of the issues addressed by students in the openquestion part of the questionnaire were related to technological aspects. For example, some students asked 
for a more intuitive graphic user interface and complained about the use of overly-technical language.

\subsection{Subject Domain.}

Two sources of data have been used to evaluate the domain acquisition of the students: the assessment of both the generated concept map and final exam questions related to the topic.

The teacher evaluated the following aspects to decide the overall mark of the concept maps: clarity, correct level and category relation and distribution, order and synthesis capability. Table d) summarizes the given score (out of a maximum of 1). Most of the students, $85 \%$, got the highest mark and no one got less than 0.5 .

\begin{tabular}{|c|c|}
\hline Score & Student percentage \\
\hline 1 & $85 \%$ \\
\hline 0.75 & $6 \%$ \\
\hline 0.5 & $9 \%$ \\
\hline 0.25 & 0 \\
\hline 0 & 0 \\
\hline
\end{tabular}

Table d). Concept Map marks

Since much more class time had been given to the attachment theory this year compared to years past, it was not easy for the teacher to compare the obtained results with previous ones. Four questions related to the topic were included in a 30-item exam this term while only 1 was included in previous years' exams.

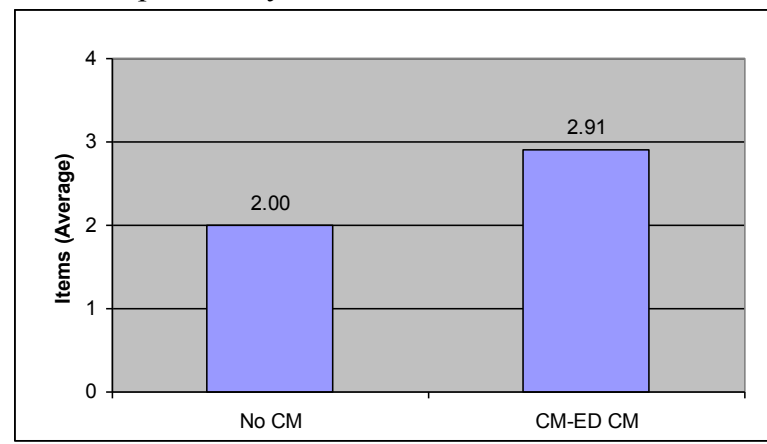

Figure 5. Number of questions answered correctly

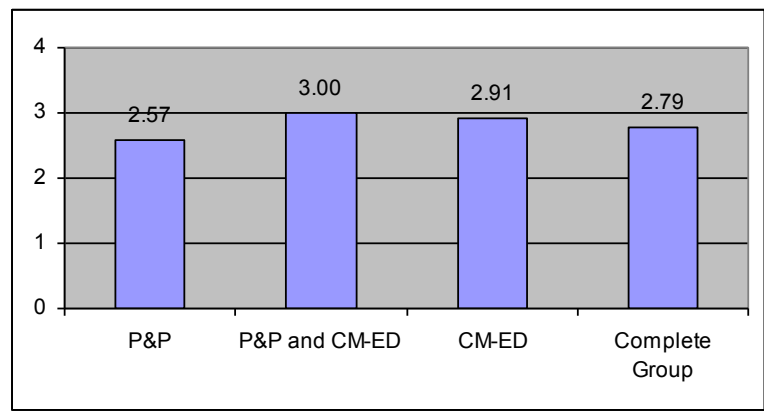

Figure 6. Number of questions answered correctly

The results of the four topic-related questions in the final exam are shown in Figure 5. Students who participated in the study and created a concept map scored better on those four questions, averaging almost one more correct answer. However, only $4.3 \%$ of the students did not draw the concept map.

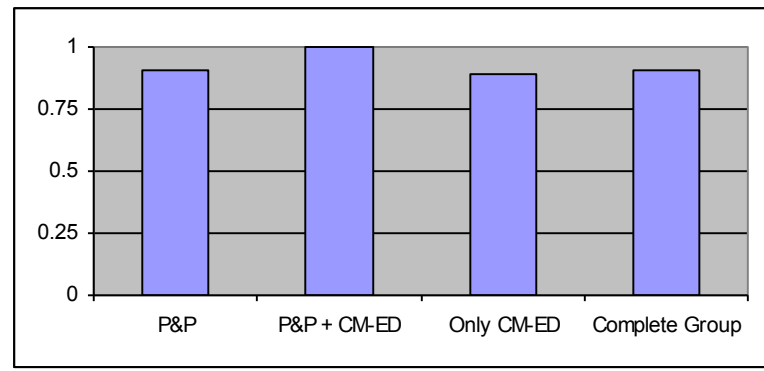

Figure 7. Concept Map marks

For example, students who worked exclusively with CM-ED or a combination of CM-ED and P\&P got better results (Figure 6). The students who used $P \& P$ first and CM-ED later most likely spent more time developing the concept map and received the maximum score of 1 point (see Figure 7). It could be concluded that students with problems using ICT could initially create a rough draft of the concept map with P\&P and later a final draft with $\mathrm{CM}$ ED, taking advantage of both approaches.

The authors also want to point out that no students got all four questions wrong and that, although the people that got the best marks in the concept map scored slightly better on the four questions, the difference is not significant.

\subsection{Non-technical degree students vs. technical degree students}

Considerable differences between students studying nontechnical and technical fields have been detected, as seen in Table e). A similar study conducted with technical degree students in the Computer Science School of the University of the Basque Country showed two main differences regarding both technical problems and subject domain learning. The study focused on the subject Introduction to Database. Students had to create a concept map containing the most important contents included in the first two chapters of the book Fundamentals of Database Systems [22]. Logically, technical difficulties were greater in the non-technical group (65\% vs. $20 \%)$. However, in spite of the problems encountered, non-technical students claimed to actually learn the topic more $(88 \%)$ than technical students $(60 \%)$. By analyzing the concept maps from both groups, the authors conclude that although they use fewer CM-ED features, students from non-technical fields construct better concept maps. Nevertheless, the concept maps created by technical students are much more schematic. It seems that not only does the technical capability of the students directly influence the concept maps, but the subject domain as well. 


\begin{tabular}{|c|c|c|}
\cline { 2 - 3 } \multicolumn{1}{c|}{} & $\begin{array}{c}\text { Difficulties with } \\
\text { CM-ED }\end{array}$ & $\begin{array}{c}\text { Subject } \\
\text { mastering }\end{array}$ \\
\hline $\begin{array}{c}\text { Non-technical } \\
\text { field }\end{array}$ & $65 \%$ & $88 \%$ \\
\hline Technical field & $20 \%$ & $60 \%$ \\
\hline
\end{tabular}

Table e). Non-technical vs. technical students

\section{Conclusion}

In this paper, a study carried out at the University of the Basque Country is presented with the aim of evaluating the CM-ED Concept Map EDitor with Social Education students. CM-ED is a multilingual and multimedia software program designed to draw concept maps.

The outcome of the study is summarized as follows:

- The most important conclusion is that, in general, students have learned not only the course content but also how to use concept map strategy.

- The disparity of student knowledge and familiarity of Concept Maps (CMs) and Information and Communication Technology (ICT) significantly affected the results. Students familiar with ICT and CM obtained higher scores.

- Another important conclusion of the study is that students unfamiliar with ICT need to have the software pre-installed and a more extensive training session. Although technical support was available during the nine weeks of the study, almost nobody asked the software instructors for assistance.

- Significant differences have been detected between students of technical and non-technical fields. Difficulties are logically greater in the second group.

In addition, a number of CM-ED improvements were identified and implemented in this study. Finally, our research has shown that students clearly did not profit from CM-ED features such as filters or multimedia resources.

In light of this project and regarding future research, the approach of applying CM-ED in real contexts will be different depending on the type and background of the students involved.

\section{References}

[1] Novak, J.D. (1977). A theory of education. Cornell University, Ithaca, NY.

[2] Taber, K.S. (1994). Student reaction on being introduced to concept mapping. Physics Education, vol. 29(5), pp. 276-281.

[3] Brandt, L., Ellen, J., Hellemans, J., Herman, L., Couwenberg, I., Volckaert, L. and Morisse, H. (2001). The impact of concept mapping and visualization on the learning of secondary school chemistry students. International Journal of Science Education, vol. 23(12), pp. 1303-1313.

[4] Afamasaga-Fuata'i, K. (2004) Concepts Maps \& Vee Diagrams as Tools for Learning New Mathematics Topics. In Concept Maps: Theory, Methodology, Technology. Proc. of the First In.l Conference on Concept Mapping. Vol. I, (eds. Cañas, A.J., Novak, J.D., González, F.M.), pp. 13-20.
[5] Marchand, C., D'ivernois, J.F., Assal, J.P., Slama, G. \& Hivon, R. (2002) An analysis, using concept mapping, of diabetic patients' knowledge, before and after patient education. Medical Teacher, vol. 24(1), pp. 90-99.

[6] Laight, D.W. (2004). Attitudes to concept maps as a teaching/learning activity in undergraduate health professional education: influenced of preferred learning style. Medical Teacher, vol. 26(3), pp. 229-233.

[7] Gul, R.B., Boman, J.A. (2006). Concept Mapping: A Strategy for Teaching and Evaluation in Nursing Education. Nurse Education in Practice, vol 6, pp. 199-206.

[8] Stoddart,, T., Abrams, R., Gasper, E. and Canaday, D. (2002) Concept maps as assessment in science inquiry learning - a report methodology. International Journal of Science Education, vol. 22(12), pp. 1221-1246.

[9] Chularut, P. and DeBacker, T. (2004) The influence of concept mapping on achievement, self-regulation, and self-efficacy in students of English as a second language. Contemporary Educational Psychology, 29(3), pp. 248-263.

[10] Leahy, R. (1989). Concept Mapping developing Guides to Literature. College Teaching, 37(2), 62-69.

[11] Hiscock, J. (2006). Breaking the Ice - Using Concept Mapping to Develop the Initial Supervisor/Student Relationship Examples from Master's Degree Students in the Social Science. Proc. of the Second Int. Conf. on Concept Mapping (eds. Cañas, A.J., Novak, J.D.), pp. 36-39.

[12] Concept Maps: Theory, Methodology, Technology. Vol. 1 and Vol. 2. Proceedings of the First International Conference on Concept Mapping (2004). Pamplona.

[13] Concept Maps: Theory, Methodology, Technology. Vol. 1 and Vol. 2. Proceedings of the Second International Conference on Concept Mapping (2006). San José, Costa Rica.

[14] Mancinelli, C., Gentili, M., Priori, G. and Valitutti, G. (2004). Concepts Maps in Kindergarten. In Concept Maps: Theory, Methodology, Technology. Proceedings of the First International Conference on Concept Mapping, (eds. Cañas, A.J., Novak, J.D., González, F.M.), Universidad Pública de Navarra, Vol. II, 265269

[15] Luckie, D. B., Harrison, S. H. and Ebert-May, D. (2004). "Introduction to C-TOOLS: Concept Mapping tools for online learning". Proceedings of the First International Conference on Concept Mapping, (eds. Cañas, A.J., Novak, J.D., González, F.M.), Universidad Pública de Navarra, Vol. II, 261-264.

[16] Cabral, A., Zeve, C. And Nicolao, M. (2004). Use of Conceptual Maps in Distance Learning Courses. In Concept Maps: Theory, Methodology, Technology. Proceedings of the First International Conference on Concept Mapping. Vol. II, (eds. Cañas, A.J., Novak, J.D., González, F.M.), Universidad Pública de Navarra, 111-114.

[17] Lupion, P. and de Cássia, R. (2004) The Contribution of Concept Maps to LOLA - The On-Line Learning Lab. In Concept Maps: Theory, Methodology, Technology. Proceedings of the First International Conference on Concept Mapping. Vol. I, (eds. Cañas, A.J., Novak, J.D., González, F.M.), Universidad Pública de Navarra, 603-610. 
[18] Gouli, E., Gogoulou, A., Papanikolaou, K. and Grigoriadou, M. (2004). "COMPASS - An Adaptive Web-Based Concept Map Assessment Tool." In Concept Maps: Theory, Methodology, Technology. Proceedings of the First International Conference on Concept Mapping. Vol. I, (eds. Cañas, A.J., Novak, J.D., González, F.M.), Universidad Pública de Navarra, 295-302.

[19] Betherton, I. (1992). The origins of attachment theory: John Bowlwy and Mary Ainsworth. Developmental Psychology, 28, pp. 759-775.

[20] Rodrigo, M.J. \& Palacios, J. (2001). Familia eta giza garapena. Bilbo: UEU.

[21] Rodrigo, M.J. \& Palacios, J. (1998). Familia y desarollo humano. Madrid: Alianza.

[22] Elmasri \& Navathe (2007). Fundamentals of Database Systems. Fifth Edition. Pearson International Edition.

Acknowledgements. This work is supported by the University of the Basque Country UPV/EHU (UE06/19), the MEC (TIN200614968-C02-01) and the Gipuzkoa Council in an EU Program. We also want to thank all the participants of this study. 


\section{Apprendix A}

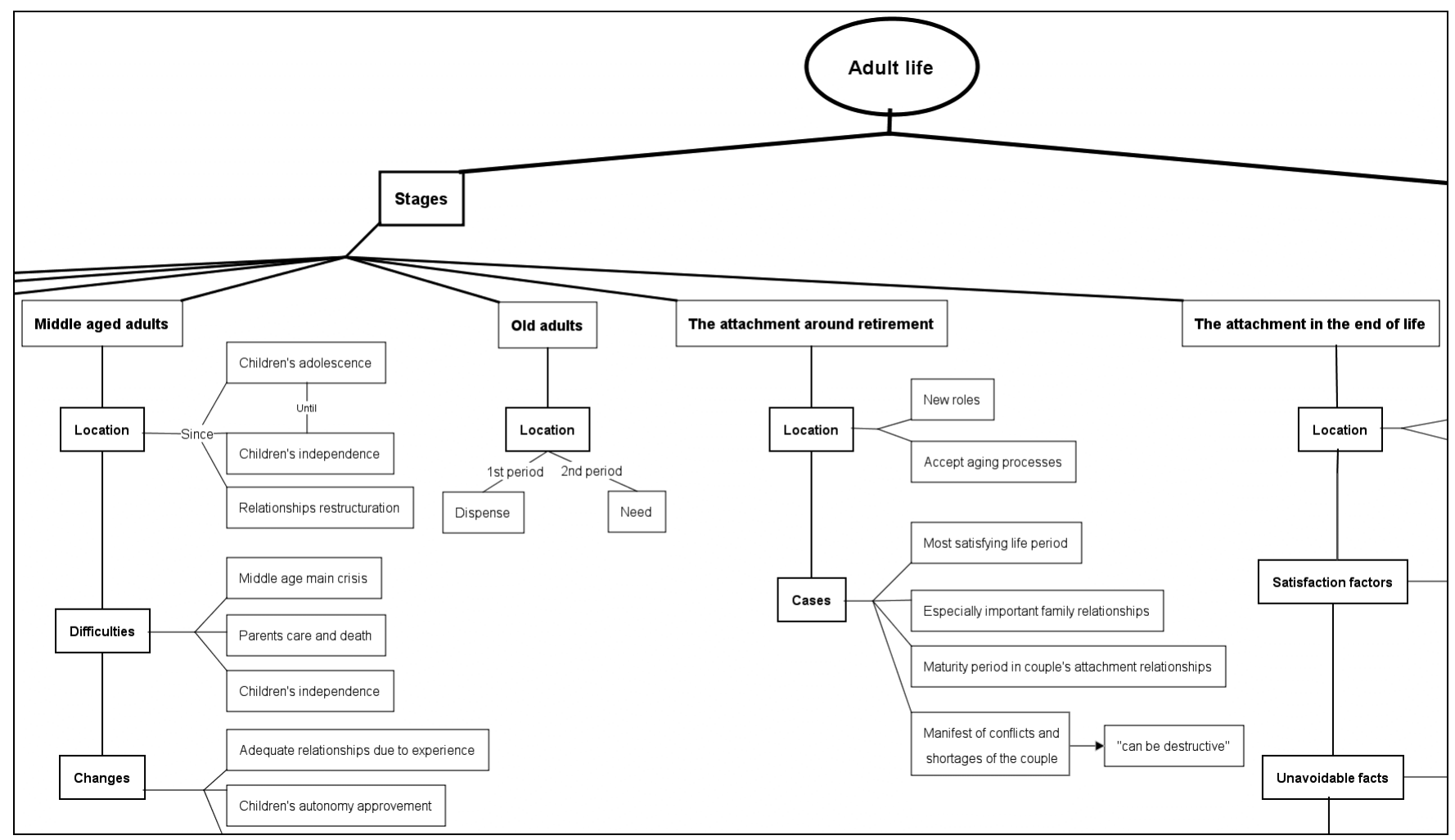

Figure8. English translation of the concept map represented in Figure 3

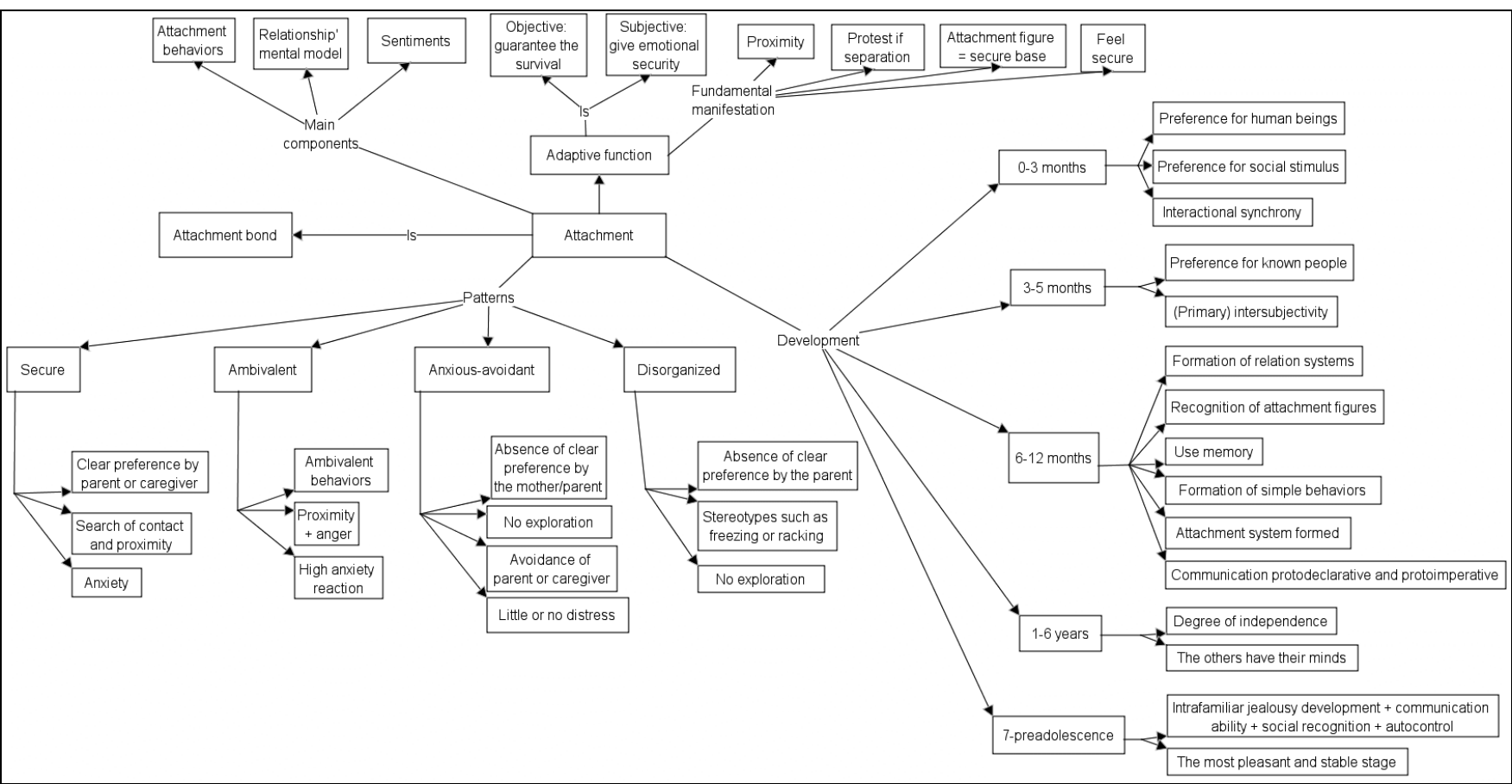

Figure9. English translation of the concept map represented in Figure 4 